American Journal of Biochemistry and Biotechnology 4 (1): 24-34, 2008

ISSN 1553-3468

(C) 2008 Science Publication

\title{
AT1-IR-beta Association: A New Mechanism for the Inhibition of Insulin Receptor Function in Breast Cancer
}

\author{
Lakshmi Pulakat, Ravindra Kolhe and Nara Gavini \\ Department of Biological Sciences, Mississippi State University, Mississippi State, MS 39762, USA
}

\begin{abstract}
Epidemiological evidence show that increased mortality in breast cancer is linked to hypertension and insulin resistance. Because Angiotensin II (Ang II), a hormone implicated in hypertension and insulin resistance, is a normal mitogen for breast tissue and elevated expression of the Ang II receptor AT1 is seen in breast cancer, we analyzed the effects of Ang II exposure on the functions of IR in human breast cancer cell line MCF-7. Exposure of MCF-7 to Ang II for 2 hours a) significantly reduced ${ }^{125} \mathrm{I}$-insulin binding to IR, and b) induced co-immuno-precipitation of the AT1 with IR-beta subunit. These Ang II-mediated effects on IR were inhibited by the AT1 antagonist losartan, and were not observed when exposure time was below 1-hour. These observations suggest extended exposure to Ang II have detrimental effects on insulin binding to IR that were not discovered in the previous studies where Ang II-exposure of insulin responsive cells was performed for periods less than one hour. In addition, they suggest a novel mechanism that involves AT1-IR-beta association for the inhibition of insulin binding to IR in response to extended exposure (2-hours) of breast cancer cells to elevated levels of Ang II (as seen in hypertensive patients), and provides a molecular link for the inhibition of normal IR signaling by Ang II in breast cancer.
\end{abstract}

Key words: Angiotensin II, AT1 receptor, Insulin receptor, Insulin, Receptor-Receptor interaction

\section{INTRODUCTION}

Several population-based studies on women suffering from breast cancer have suggested that other metabolic disorders such as hypertension, insulin resistance, obesity and metabolic syndrome increase the complications associated with cancer or contribute to breast cancer risk ${ }^{[1-6]}$. In addition, a recent study has shown that women previously diagnosed with breast cancer are at an increased risk of developing type II diabetes, a condition to which insulin resistance is central $^{[7]}$. While these observations imply a strong interrelationship between breast cancer, hypertension, and insulin resistance, what signaling mechanisms contribute to such relationship in breast tissue are yet to be elucidated. One of the hormones that promote mitogenic signaling pathways of normal breast cells as well as breast cancer cells is Ang $\mathrm{II}^{[8-11]}$. Components of Renin-Angiotensin System (RAS) are expressed in breast tissue implying existence of local Ang II production and subsequent activation of Ang II receptors. Expression of the Ang II receptor AT1 is observed in both normal and cancerous breast cells. More importantly, the AT1 receptor expression is shown to be elevated in breast hyperplasia and in situ carcinoma implying that increased AT1 signaling could contribute to complications associated with breast cancer $^{[11]}$. In contrast, women with low-activity genotype of the ACE gene who show reduced Ang II hormone have significantly reduced risk of breast cancer $\left(50 \%\right.$ lower ${ }^{[12]}$.

The Ang II and the AT1 receptor are also known to be contributing factors for insulin resistance in hypertensive and diabetic patients, as well as those with metabolic syndrome ${ }^{[13-16]}$. The role of Ang II, a multifunctional peptide hormone that regulates blood pressure and body fluid homeostasis, in the development of hypertension and other cardiovascular diseases is well established ${ }^{[17-19]}$. In addition, recent studies that show blockers of ACE (Angiotensin Converting enzyme) and antagonists of AT1 receptor are capable of reducing insulin resistance in human patients have highlighted the possible role of Ang II and AT1 in the development of insulin resistance. Similar results have also been obtained in studies with spontaneously hypertensive rats and in mice models with type II diabetes $[15,16,20-25]$. These results imply existence of cross-talk between the Ang II- and Insulinsignaling pathways.

Corresponding Author: Lakshmi Pulakat, Department of Biological Sciences, Mississippi State University, Mississippi State, MS 39762 
The AT1 is a 359 amino acid protein with a seven transmembrane domain (7-TMDs) topology ${ }^{[26]}$. Ang IImediated AT1 activation results in Gq/11-stimulation and subsequent activation of Phospholipases C, and D, phospholipids hydrolysis, increase in intracellular $\mathrm{Ca}^{2+}$, activation of Protein Kinase C isoforms, MAP kinases, and tyrosine kinases such as Pyk2, Src, Tyk2 and $\mathrm{FAK}^{[26-29] .} \quad$ This constitutes the main signaling mechanism of AT1. AT1 also directly interacts with Jak2 via the C-terminal YIPP motif ${ }^{[30,31]}$. In addition, the AT1 is known to form heterodimers with other 7TMD proteins such as Bradykinin B2 receptor and the second Ang II receptor AT2 $2^{[32,33]}$ and transactivate the Epidermal Growth Factor Receptor (EGFR) ${ }^{[34]}$. The activation by AT1 of EGFR is caused by transient interaction between the AT1 and the EGFR within 3minutes of Ang II-exposure and tyrosine phosphorylation of EGFR. The AT1-activated Src kinase is involved in this AT1-EGFR association and EGFR tyrosine phosphorylation ${ }^{[34]}$. Thus recruiting Receptor Tyrosine Kinases (RTKs) such as EGFR into its signaling is another mechanism by which the AT1 contributes to stimulating cell growth.

The Insulin receptor (IR) is a heterotetrameric receptor tyrosine kinase that activates several signaling pathways in response to insulin binding [35-38]. The first step in the activation of IR is insulin binding; therefore, conditions that lead to inhibition of insulin binding results in the lack of IR signaling and subsequent development of insulin resistance. A unique feature of the insulin resistance is that it is a silent condition that often remains undetected until too late ${ }^{[13,14,39]}$. In addition it is the central component of Non-Insulin Dependent Diabetes Mellitus and Metabolic Syndrome, conditions that contribute to complications of breast cancer risk and breast cancer progression. Because elevated expression of AT1 is seen in breast cancer and it is involved in the development of insulin resistance, we analyzed whether or not the Ang II and the AT1 act as molecular links that connect breast cancer and inhibition of IR signaling that leads to insulin resistance.

The human breast cancer cell line MCF-7 derived from the pleural effusion of adenocarcinoma is widely used as a model for studying signaling in breast cancer [40]. In MCF-7 cells, Ang II binding to AT1 induces cell growth via extracellular signal regulated kinase (ERK1/2) activity ${ }^{[9]}$. Thus, Ang II is a mitogen of these cells. This ERK1/2 activation is shown to occur via protein kinase $\mathrm{C}$ and epidermal growth factor receptor $(\text { EGFR })^{[9,41,42]}$. It has also been shown that Ang IImediated activation of ERK1/2 can also occur in an
EGFR-independent manner because AG1478, the selective EGFR receptor tyrosine kinase blocker, did not abolish the Ang II-induced ERK1/2 activation in MCF-7 cells ${ }^{[43]}$. This observation implies that apart from EGFR, other Receptor Tyrosine Kinases could also be activated by Ang II in MCF-7 cells. Interestingly, it is also shown that ERK1/2 activation by Ang II is higher in insulin resistant hypertensive patients ${ }^{[44]}$. Because of such similarities in Ang IImediated signaling in breast cancer cells and signaling observed in insulin resistant patients, we tested whether or not the Ang II and the AT1 act as molecular links that connect breast cancer, hypertension, and insulin resistance. We used the MCF-7 cells as the model system. The studies reported here demonstrate for the first time that the ligand-activated AT1 forms a complex with IR and prevents the first step in IRsignaling, namely insulin binding to IR.

\section{MATERIALS AND METHODS}

Materials: The MCF-7 cell line was purchased from American Type Culture Collection (ATCC) and was grown in $90 \%$ Minimum Essential Medium supplemented with $2 \mathrm{mM}$ L-glutamine, $1.5 \mathrm{~g} / \mathrm{L}$ sodium bicarbonate, $0.1 \mathrm{mM}$ non-essential amino acids and $1 \mathrm{mM}$ sodium pyruvate and $10 \%$ Fetal bovine serum (from ATCC) at $37^{\circ} \mathrm{C}$. Human Angiotensin II was purchased from Sigma Inc. (St. Louis, MO, USA) and the AT1-specific antagonist Losartan (DuP753) was obtained from Merck \& Co., Inc. (Whitehouse Station, NJ, USA). All primary antibodies and agaroseconjugated antibodies were from Santa Cruz Biotechnology, Inc. (Santa Cruz, CA) and the ECL Western Blot kit was from Amersham Biosciences. Bio-Rad DC Protein Assay kit was from BioRad laboratories. Hercules, CA. ${ }^{125}$-I-labeled Insulin was from NEN Life Science Products (Boston, MA, USA).

Cell culturing: For all experiments, MCF-7 cells (from ATCC) were grown in complete medium (Minimum Essential Medium supplemented with 10\% FBS (both from ATCC) to $90 \%$ confluency. The cells were then washed repeatedly with PBS to remove traces of complete medium, and were incubated in the presence of serum-free medium containing appropriate amounts of Ang II. For treatment with AT1 antagonist losartan, the cells were pre-treated for 15 minutes with $1 \mu \mathrm{M}$ losartan (in serum-free medium) prior to the addition of $100 \mathrm{nM}$ Ang II, and then incubated for a period of 2hours. For treatment with anti-insulin antibody, the cells were simultaneously incubated with $4 \mu \mathrm{g} / \mathrm{ml}$ of anti-insulin antibody and 100nM of Ang II for 2-hours. 
The ligand-exposure was ended by washing with PBS repeatedly and collecting the cells via gentle trypsinisation.

${ }^{125}$ I-Insulin binding: To measure ${ }^{125}$ I-insulin binding to IR in MCF-7 cells before and after Ang II treatments, cells were collected before and after treatment with appropriate ligand-combinations for the concentrations and the times indicated in the figures. ${ }^{125} \mathrm{I}$-insulin binding was carried out as follows: The MCF-7 cells $\left(10^{5}\right.$ cells, with or without pre-treatment with appropriate concentrations of Ang II, or Ang II $+1 \mu \mathrm{M}$ losartan,) were washed with PBS repeatedly, and resuspended in $100 \mu \mathrm{l}$ of pre-incubation medium ${ }^{[46,47]}$. The pre-incubation medium contained protease inhibitor cocktail to prevent degradation of Ang II. When losartan was used, it was added to the preincubation medium (at a concentration of $1 \mu \mathrm{M}$ ) to ensure its effects are not removed by PBS washing. After a 15 minute pre-incubation, the cells were freshly re-suspended in same medium containing 100picoMoles ${ }^{125} \mathrm{I}$-insulin and the binding was carried out for one hour at $37^{\circ} \mathrm{C}$. At the end of 1 -hour incubation, the cells were collected by centrifugation, washed repeatedly by PBS, and the radioactivity was monitored using Beckman LC6800 liquid scintillation counter. To determine non-specific binding, the binding was performed in the presence of nonradioactive insulin $(1 \mu \mathrm{M})$. The binding obtained for the untreated sample under these conditions $\left(\sim 0.9 \times 10^{8}\right.$ molecules) was taken as $100 \%$. The $\%$ of binding to other samples in comparison with the untreated sample was calculated. Experiments were repeated with multiple samples (at least 3 for each data point. To determine the lowest level of Ang II to achieve $50 \%$ inhibition of ${ }^{125} \mathrm{I}$-insulin binding to IR in MCF-7 cells, the cells were treated with Ang II concentrations ranging from $10 \mathrm{pM}$ to $1 \mu \mathrm{M}$. Student $t$ test was employed to determine the statistical significance of the differences observed in the binding experiments.

Immunoprecipitation, Western blotting and Detection: Immunoprecipitation experiments were carried out as described previously ${ }^{[49]}$. The protein concentrations of the lysates were determined using Bio-Rad DC Protein Assay kit. The protein concentrations were adjusted to be same in all lysates by dilution with appropriate amounts of PBS. The lysates of MCF-7 cells that were not exposed to Ang II served as negative controls. Lysates were divided into two parts; one part was used for immunoprecipitation experiments and the other was used for determining the levels of AT1 and IR in each of the lysates by immunoblotting with appropriate antibodies. The lysates used for immunoprecipitation experiments were adjusted to have same volumes and contained $800 \mu \mathrm{g}$ of protein before immunoprecipitation. The IR-beta was immunoprecipitated from these lysates using agarose conjugated rabbit anti-IR-beta antibody. Immunoprecipitated proteins were separated on $10 \%$ SDSpolyacrylamide gel and subjected to immunoblotting with goat anti-AT1 antibody to test whether or not the AT1 could co-precipitate with IR-beta subunit. BioRad Protein molecular weight marker was also loaded in one of the lanes of the SDS-PAGE gels used for separation of the proteins and the lane containing the marker was cut out from the gel and subjected to coomassie blue staining to locate the positions of proteins with different molecular weights. The stained gel piece carrying the protein molecular weight marker was then compared to the image on the autoradiogram to identify the molecular weights of the bands visualized by anti AT1 antibody. ECL Western Blotting Analysis System (Amersham Biosciences) was used to visualize the presence of the AT1 or IR in the immunoblots generated according to manufacturer's instructions. To determine the protein concentrations of AT1 or IR in MCF-7 cells exposed to Ang II, lysates of all samples were adjusted to have same volumes and contain $200 \mu \mathrm{g}$ protein. Proteins in the lysates were separated by SDS-PAGE, and subjected to immunoblotting with anti-AT1 antibody or anti-IR-beta antibody. Protein molecular weight markers were used as described above to determine the molecular weights of the bands visualized by the Anti-AT1 antibody or anti-IR-beta antibody in the resulting autoradiogram. The NIH Image Scan (Image J) program was used to quantify the intensity of the bands present on the autoradiogram that were made visible by probing with the anti-AT1 or anti-IR-beta antibodies.

\section{RESULTS}

Effects of Exposure to Ang II and AT1-antagonist Losartan on the ${ }^{125}$ I-insulin binding to IR in human breast cancer cell line MCF-7: The primary event in insulin-signaling is insulin binding to the IR. Inhibition of insulin binding to IR can contribute to insulin resistance. Since insulin resistance is often a contributing factor to poor prognosis in breast cancer, we analyzed whether or not exposure to Ang II had any effect on the ${ }^{\mathrm{I} 25} \mathrm{I}$-insulin binding to IR present in the breast cancer cell line MCF-7. Ligand binding 
Am. J. Biochem. \& Biotechnol., 4 (1): 24-34, 2008

experiments were performed as described in Experimental procedures.

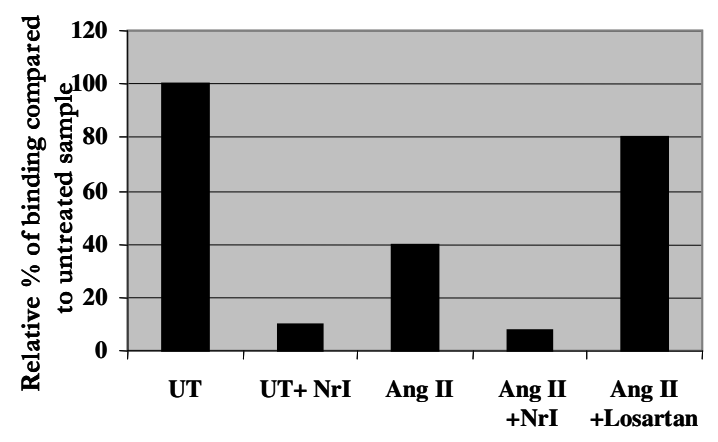

(a)

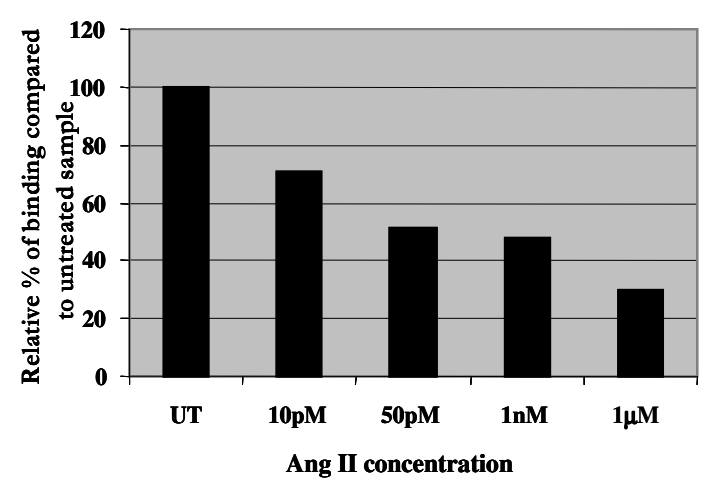

(b)

Fig. 1. a): A 2-hour pre-treatment with Ang II prevent ${ }^{125}$ I-insulin binding to IR in human breast cancer cell line MCF-7. Relative $\%$ of ${ }^{125}$ I-insulin binding to IR on MCF-7 cells exposed to Ang II under different conditions is shown. The binding for cells that were not exposed to Ang II (UT:Untreated) was taken as $100 \%$. UT+NrI: Untreated in the presence of $1 \mu \mathrm{M}$ of non-radioactive insulin as competitor; Ang II: pre-treated with 100nM Ang II for a period of 2 hours before exposing to ${ }^{125}$ I-insulin; Ang II $+\mathrm{NrI}$ : pre-treated with $100 \mathrm{nM}$ Ang II for a period of 2 hours before exposing to ${ }^{125} \mathrm{I}$-insulin binding in the presence of $1 \mu \mathrm{M}$ of non-radioactive insulin.; Ang II+ Losartan: pretreated with $100 \mathrm{nM}$ Ang II $+1 \mu \mathrm{M}$ of losartan before exposing to ${ }^{125}$ I-insulin. Results shown here were derived from individual experiments using at least three sets of samples of MCF-7 cells maintained in serum-free medium for 2 hours in the presence or absence of appropriate ligands for ${ }^{125}$ I-insulin binding. This procedure was further repeated at least three times. Student's $t$-test showed that $P$ is less than 0.001 for the differences observed between the extent of ${ }^{125}$ I-insulin binding to: (1) MCF-7 cells in the absence of any ligands (UT) and MCF-7 cells treated with $1 \mu \mathrm{M}$ nonradioactive insulin during ligand-binding experiment (UT+ $\mathrm{NrI}$ ), (2) sample UT and MCF-7 cells pre-treated with 100nM Ang II for 2 hours (AngII) (3) sample Ang II and sample UT+ NrI, (4) sample Ang II and MCF-7 cells treated with $100 \mathrm{nM}$ Ang $+1 \mu \mathrm{M}$ insulin (Ang II+ NrI) during ligand-binding experiment, (5) sample UT and MCF-7 cells pre-treated with $100 \mathrm{nM}$ Ang II $+1 \mu \mathrm{M}$ losartan, (6) sample UT+ NrI and MCF-7 cells pre-treated with 100nM Ang II+ $1 \mu \mathrm{M}$ losartan, (7) sample Ang II and MCF-7 cells pretreated with $100 \mathrm{nM}$ Ang II+ $1 \mu \mathrm{M}$ losartan, (8) sample AngII+ NrI and MCF-7 cells pre-treated with 100nM Ang II $+1 \mu \mathrm{M}$ losartan, Standard errors for each data point came within $3 \%$. b): Inhibition of ${ }^{125} \mathrm{I}$-insulin binding to IR present on MCF-7 cells pre-exposed to different concentrations of Ang II for 2 hours. Concentrations of Ang II are shown on the $\mathrm{X}$-axis. Relative\% of binding to each sample compared to that of untreated MCF-7 cells is shown. Data was collected using similar procedures described for Fig. 1a. Triplicates of treated and untreated of MCF-7 cells were used for each experiment and the experiments were performed at least 3 times. Student's $t$-test showed that $P$ is less than 0.001 for the differences observed between the extent of ${ }^{125}$ I-insulin binding to: (1) MCF-7 cells in the absence of any ligands and MCF-7 cells treated with either $10 \mathrm{pMoles}$, 50pMoles, $1 \mathrm{nMole}$ and $1 \mu \mathrm{M}$ of AngII. Similarly, Student's $t$-test also showed that $P$ is less than 0.001 for the differences observed between the extents of ${ }^{125}$ I-insulin binding to MCF-7 cells treated with different concentrations of Ang II. Standard errors for each data point were less than $4 \%$.

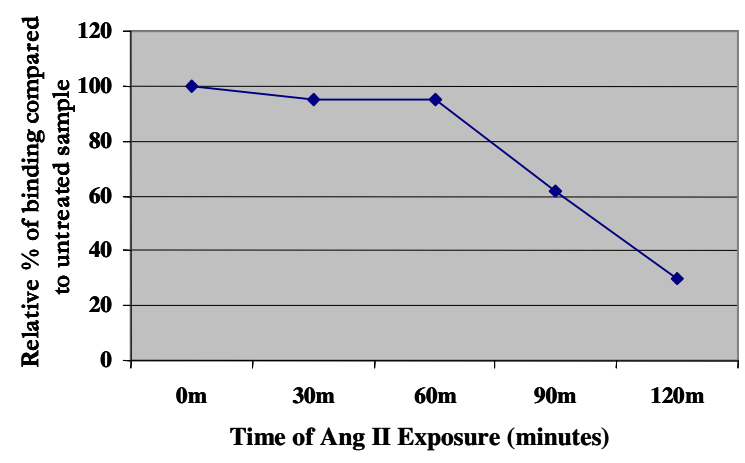

(a)

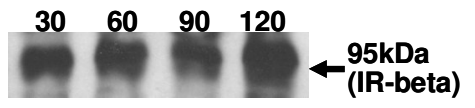

(b)

Fig. 2. a): Ang II-mediated inhibition of ${ }^{125}$ I-insulin binding to IR present on MCF-7 cells starts only after one-hour pre-exposure to Ang II. Experimental conditions and data collection procedures are identical to those described for Fig. 1 a) and b). Pre-exposure times used to induce Ang II-mediated inhibition of ${ }^{125} \mathrm{I}$ insulin binding are shown on X-axis. Student's $t$ test was used to determine the significance and was found that $P$ is less than 0.001 for the differences observed between the extent of ${ }^{125} \mathrm{I}$-insulin binding to untreated of MCF-7 cells and MCF-7 cells treated with $1 \mu \mathrm{M}$ Ang II for a period of 90 minutes or 1 hour. Standard errors for each data point were less than 3\%. b): Exposure to $100 \mathrm{nM}$ Ang II did not result in reduction of IR protein levels in MCF-7 cells. Autoradiogram shows the levels of IR-beta subunit in the lysates of MCF-7 cells exposed to 
100nM Ang II for different time periods (30 minutes, 60 minutes, 90 minutes, and 120 minutes). $200 \mu \mathrm{g}$ of protein from each lysate was subjected to SDS-PAGE, Western blotting and probing with anti-IR-beta antibody. A $95 \mathrm{kDa}$ band of comparable intensity corresponding to the molecular weight of the IR-beta subunit was visible in all lanes indicating that total protein levels of IR were not affected by Ang II treatment.

The initial experiments using $100 \mathrm{pMoles}$ of ${ }^{\mathrm{I} 25} \mathrm{I}-$ insulin showed that we could consistently get binding of $\sim 0.9 \times 10^{8}$ molecules of ${ }^{125} \mathrm{I}$-insulin to these samples under these conditions. The ${ }^{125}$ I-insulin-binding to these samples was reduced by about $90 \%$ when the binding was performed in the presence of 10,000 fold excess of non-radioactive insulin $(1 \mu \mathrm{M}$ non-radioactive insulin) (Fig. 1a). Therefore, 90\% of the ${ }^{125}$ I-Insulinbinding observed in these experimental conditions is due to specific binding $\mathrm{f}$ insulin to its receptor. However, in the Ang II- treated samples (in the absence of non-radioactive insulin), the binding was reduced by about $60 \%$ (Fig. 1a). This observation implied that Ang II acting through the AT1 receptor is causing a change in IR that results in the inhibition of ${ }^{125}$ I-insulin binding to IR in human breast cancer cells that express AT1. In MCF-7 cells treated with Ang II in the presence of AT1 antagonist losartan, the binding was reduced only by $20 \%$ (Fig. 1a). Therefore $40 \%$ of the Ang II-induced reduction in the ${ }^{125}$ I-insulin-binding to its receptor was recovered by the treatment with AT1-antagonist losartan. This observation further supported the idea that the Ang II-mediated inhibition of ${ }^{125}$ I-insulin-binding to IR is primarily mediated through the AT1 receptor, because the AT1 antagonist losartan could inhibit this effect substantially. Because Ang II is locally available in breast tissue, our results imply that the increased AT1 expression observed in hyperplasia and in situ carcinoma conditions can contribute to AT1-mediated inhibition of insulin binding to a substantial population of IR (up to 60\%) in breast cancer. This can lead to lack of IR signaling in breast cancer tissue. Moreover, it can also cause inhibition of clearing of insulin, because binding of insulin to IR is part of the mechanism needed to clear insulin from blood. To our knowledge, this is the first report that shows Ang II-activated AT1 causes inhibition of insulin binding to IR in human breast cancer cells

Determination of the lowest concentration of Ang II needed to inhibit $50 \%$ of ${ }^{125}$ I-insulin binding to IR: To identify the lowest concentration of Ang II that can induce inhibition of insulin binding to IR in

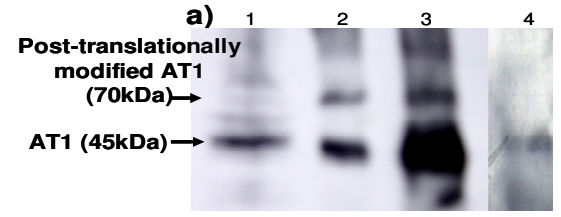

b)

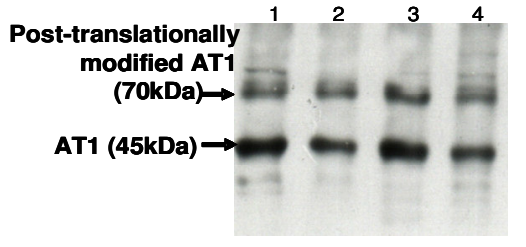

e)
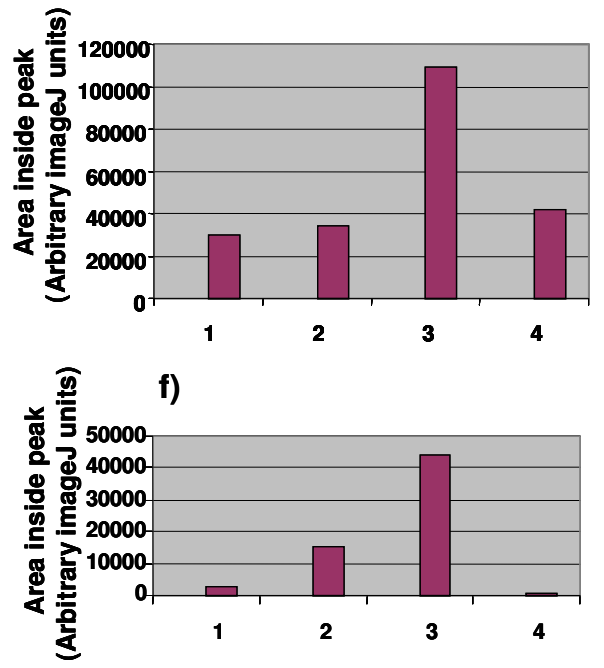

c)

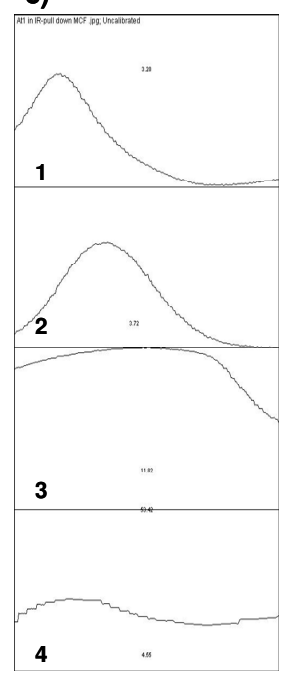

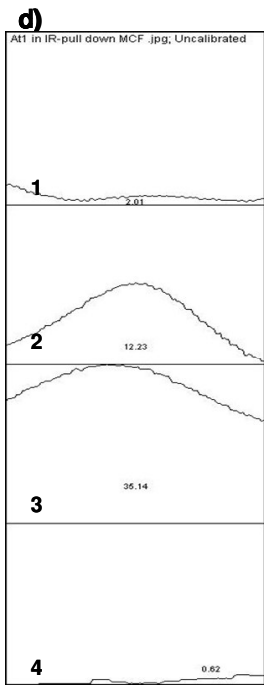




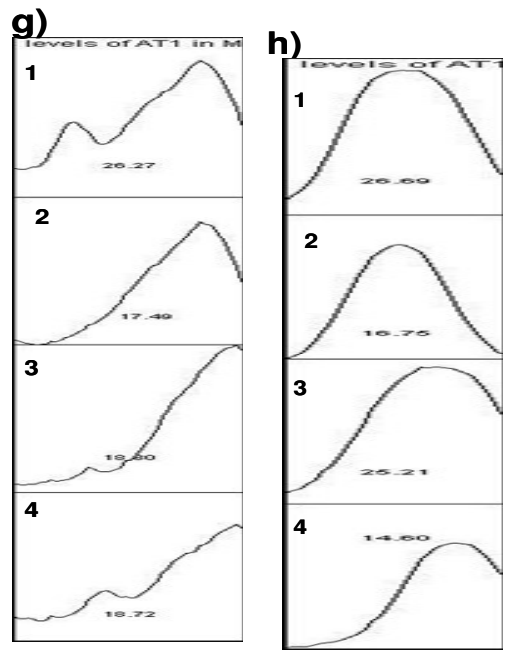

Fig. 3. Ang II induces AT1-IR association. a) An example of the autoradiogram that shows that the AT1 co-precipitates with IR-beta subunit from lysates of MCF-7 cells in response to exposure to100nM Ang II for a period of 2-hours, and the AT1 antagonist losartan inhibits this effect: the lysates used were from MCF-7 cells that were not exposed to Ang II (lane 1), exposed to 100nM Ang II for $60 \mathrm{~min}$ (lane 2), exposed to $100 \mathrm{nM}$ Ang II for 2 hours (lane 3), and exposed to $100 \mathrm{nM}$ Ang II $+1 \mu \mathrm{M}$ AT1 antagonist losartan for 2 hours (lane 4). Initial protein concentration used for immunoprecipitation with IR-beta subunit was same in all lysates $(800 \mu \mathrm{g})$. A low molecular weight band of $45 \mathrm{kDa}$ and a high molecular weight band of $70 \mathrm{kDa}$ were visualized by probing with antiAT1 antibody. b) Autoradiogram of the immunoblot showing the levels of AT1 protein in all of the lysates used for the experiment described in a). The lysates used were from MCF-7 cells that were not exposed to Ang II (lane 1), exposed to $100 \mathrm{nM}$ Ang II for $60 \mathrm{~min}$ (lane 2), exposed to $100 \mathrm{nM}$ Ang II for 2 hours (lane 3), and exposed to $100 \mathrm{nM}$ Ang II $+1 \mu \mathrm{M}$ AT1 antagonist losartan for 2 hours (lane 4). In each lane $200 \mu \mathrm{g}$ of protein was loaded. Both $45 \mathrm{kDa}$ band and $70 \mathrm{kDa}$ band were visible after probing the Western blot with the anti-AT1 antibody. Figs c) \& d) show the graphs generated by NIH imageJ scans of the $45 \mathrm{kDa}$ and $70 \mathrm{kDa}$ bands in lanes 1 to 4 the autoradiogram shown in a). (from top to bottom labeled as 1- 4). Figs. e) \& f) show the area under each peak in Figs c) \& d) in NIH imageJ arbitrary units which correspond to the intensities of the $45 \mathrm{kDa}$ and $70 \mathrm{kDa}$ bands in lanes 1-4 in the autoradiogram shown in a). Experiments were repeated twice and measurements were repeated four times. Significance was determined by Student's $t$-test. $P$ is less than 0.001 for the fold increases reported. The $45 \mathrm{kDa}$ band showed a five fold increase in intensity and the $70 \mathrm{kDa}$ band showed a 15 fold increase in intensity in the lysates of MCF-7 cells exposed to Ang II for 2 hours. Standard deviations were within 5\%. Figures g) and h) show the graphs generated by NIH imageJ scan of the $70 \mathrm{kDa}$ band and $45 \mathrm{kDa}$ band respectively in lanes $1-4$ of the autoradiogram shown in Fig. b). The peaks corresponding to the levels of AT1 protein present in these bands (in the lysates of MCF-7 cells) before exposure to Ang II (lane 1, Fig.b) and after 2-hour exposure to Ang II (lane 3, Fig. b) were found to be comparable.
MCF-7 cells, we tested the effects of different concentrations of Ang II on the ${ }^{125} \mathrm{I}$-insulin-binding to IR. The exposure time was maintained same ( 2 hours) in these experiments. We found that exposure to 50picoMoles of Ang II could induce 50\% inhibition of ${ }^{125}$ I-insulin-binding to IR, although the concentration of ${ }^{125} \mathrm{I}$-insulin used in these experiments (100picoMoles) was twice the amount of Ang II (Fig. 1b). This observation strongly suggested that small fluctuations in the levels of Ang II can induce lack of insulin binding to IR, a pre-diabetic condition in breast cancer cells. It also implies that because tissues such as breast and ovary can produce Ang II, and many stimuli can cause small fluctuations in serum-Ang II levels, breast cancer cells with elevated AT1 expression can be predisposed to develop insulin resistance.

Determination of the minimum time of exposure to Ang II needed to inhibit $50 \%$ of ${ }^{125}$ I-insulin binding to IR: In our experiments, Ang II-induced inhibition of insulin binding to IR was observed after a 2-hour incubation of MCF-7 cells in the presence of Ang II. Previous studies with other cell types have employed exposure times up to one-hour to Ang II; however, such treatment did not reduce insulin binding to the $\mathrm{IR}^{[48]}$. To further determine the time-frame for Ang IIinduced inhibition of insulin binding to IR in breast cancer cells, we analyzed the effects of shorter time exposure to Ang II on insulin binding to IR in MCF-7 cells. In these experiments, the MCF-7 cells were exposed to Ang II for shorter time periods (Fig. 2a). No inhibition of the ${ }^{125} \mathrm{I}$-insulin binding to IR was observed for one hour (Fig.2a) in spite of using $1 \mu \mathrm{M}$ Ang II to maximize the inhibition effect. Only after one hour, the ${ }^{125} \mathrm{I}$-insulin binding to IR started decreasing and $70 \%$ of the binding was lost by 2 hours (Fig. 2a). These observations suggested that Ang IIinduced inhibition of insulin binding to IR in breast cancer cells requires exposure to Ang II for more than one hour. Taken together, our results suggest that Ang II-induced inhibition of insulin binding to IR can occur when the breast cancer cells are exposed to Ang II continuously (for more than one hour) at concentrations as low as 50picoMoles. This observation is particularly noteworthy in the cases of patients suffering from conditions in which RAS is hyperactive. These include hypertension, obesity and metabolic syndrome, factors that contribute to high mortality among breast cancer patients.

Because these experiments involved washing the MCF-7 cells to remove the FBS containing medium and maintaining the cells in the absence of FBS and in 
the presence of 100nM Ang II in Minimum Essential Medium for a period of 2 hours, we tested whether or not this treatment had any effect on the IR protein levels. MCF-7 cell lysates containing $200 \mu \mathrm{g}$ of protein (as determined by BioRad DC protein assay) were subjected to SDS-PAGE, Western blotting and probing with anti-IR-beta antibody. It was observed that placing the cells in serum-free Minimum Essential Medium containing 100nM of Ang II for 2 hours did not change the protein levels of IR-beta (Fig. 2b). This observation implied that a 2-hour exposure to Ang II did not result in a general reduction in the levels of total IR-beta protein and therefore the reduced binding of ${ }^{125} \mathrm{I}$-insulin to IR could have resulted from an ATmediated effect that affects either the affinity of IR or the availability of functional IR that can bind insulin.

Determination of AT1-IR complex formation in response to exposure to Ang II: As mentioned earlier, although the AT1 is a G-protein coupled receptor (GPCR), it also functions in a G-protein independent manner. Notable among its G-protein independent signaling mechanisms is its activation of the EGFR, a Receptor Tyrosine Kinase ${ }^{[34]}$. In MCF-7 cells it has been shown that Ang II stimulates cell growth and this effect is mediated by transactivation of EGFR and subsequent activation of ERK1/2 ${ }^{[9]}$. These Ang IImediated effects were observed in MCF-7 cells within few minutes of Ang II exposure. In COS-7 cells it has been shown that Ang II induces coimmunoprecipitation of the AT1 with EGFR ${ }^{[34]}$. This AT1-EGFR association was found to be transient (seen after 3 minutes incubation in the presence of Ang II and disappeared when the exposure was continued for 5 minutes $)^{[34]}$. In our experiments, AT1-mediated inhibition of insulin binding to IR did not occur during the time-frame required (within minutes) for transactivation of EGFR in MCF-7 cells or COS-7 cells suggesting that the mechanisms involved in AT1mediated inhibition of insulin binding to IR should be different from that required for EGFR transactivation. However, because the IR is also a Receptor Tyrosine Kinase (RTK) similar to EGFR, we tested whether or not the AT1 could associate with IR-in response to Ang II exposure in MCF-7 cells. Therefore, IR-beta subunit from the MCF-7 cells that were exposed to Ang II in the absence of insulin for different time periods was immunoprecipitated and was immunoblotted with the anti-AT1 antibody (Fig. 3a). It was found that in MCF7 cells exposed to Ang II for 2 hours, the AT1 coprecipitated with the IR beta as evidenced by the intense, broad band corresponding to the molecular weight of about $45 \mathrm{kDa}$ (Fig. 3a, lane 3). In addition, a high molecular weight band (about $70 \mathrm{kDa}$ ) also interacted with the anti-AT1 antibody and its intensity also increased in response to 2-hour Ang II exposure. Such high molecular weight AT1 peptides are suggested to result from differential glycosylation ${ }^{[48]}$. Coprecipitation of both $45 \mathrm{kDa}$ AT1 peptide and $70 \mathrm{kDa}$ AT1 peptide with IR was very low in the absence of Ang II exposure (Fig. 3a, lane1) and when the cells were pre-treated with $1 \mu \mathrm{M}$ losartan, an AT1 specific antagonist (Fig. 3a lane 4). Since there was a clear increase in the levels of AT1 that co-precipitated with IR-beta in a time-dependent manner in response to exposure to Ang II, and this effect was abolished by the losartan, next we tested whether or not 2-hour exposure to Ang II increased the levels of the AT1 in these cells. Lysates of MCF-7 cells used for the experiment shown in Fig. 3a were subjected to immunoblotting using antiAT1 antibody. An example of the autoradiogram resulting from such immunoblot analyses is shown in Fig. 3b. It was observed that the immunoprecipiate generated from MCF-7 cells before (lane 1) and after (lanes $2 \& 3$ ) exposure to Ang II, or after treatment with losartan + Ang II (lane 4) contained both 45kDa and 70kDa AT1 peptides (Fig. 3b).

NIH imageJ scan analysis ${ }^{[50]}$ was performed on these autoradiograms to quantify the differences between the levels of the AT1 that co-precipitated with the IR-beta in these samples. An example of the plots of the co-precipitated lower AT1 band (corresponding to proteins in the range of molecular weight of about 45 $\mathrm{kDa}$ ) is shown in Fig. 3c. The Fig.3e shows the differences between the areas under each of the NIH imageJ generated peak corresponding to the intensity of the bands within the range of molecular weight of about $45 \mathrm{kDa}$. It was clear that the levels of $45 \mathrm{kDa}$ AT1 peptide that co-precipitated with the IR-beta after onehour treatment with Ang II was slightly higher than that from the cells that were not treated with Ang II (Fig. 3a, compare lanes 1 and 2, Fig. 3c and Fig. 3e) and about 5 fold higher than that from the cells that were exposed to Ang II for 2-hours (Fig. 3a, compare lanes 1 and 3, Fig. $3 \mathrm{c}$ and Fig. 3e). This 5-fold increase was abolished in losartan-treated cells ((Fig. 3a, compare lanes 1and 4, Fig. 3c and Fig. 3e). An example of the plots of the coprecipitated upper AT1 band (corresponding to proteins in the range of molecular weight of about $70 \mathrm{kDa}$ ) is shown in Fig. 3d. The Fig. 3f shows the differences between the area under each of the NIH imageJ generated peak corresponding to the intensity of the bands visualized by probing with anti-AT1 antibodies and within the range of molecular weight of about 
$70 \mathrm{kDa}$. The presence of this band was negligible in the cells that were not exposed to Ang II and after treatment with losartan. However, the intensity of this band increased by about 5-fold when the cells were exposed to Ang II for one hour and by about 15 fold when the cells were exposed to Ang II for 2 hours (Fig. 3d and 3f). These observations suggested that Ang II induces AT1-IR association in epithelial cells such as human breast cancer cell line MCF-7, and AT1 peptides with or without post-translational modifications associate with IR in response to Ang II. Moreover, they implied that the AT1 receptors undergo extensive posttranslational modifications that result in high molecular weight bands in breast cancer cell line such as MCF-7. This Ang II-induced AT1-IR association requires about 2 hours of exposure to Ang II, and is dissimilar to AT1EGFR association that occurs transiently with in 3minutes of exposure to Ang II. Collectively, these observations suggest that the Ang II-activated AT1 associates with IR-beta and sequesters IR-beta in a complex, and AT1-antagonist losartan inhibits this effect. In addition, our results also imply that the signaling that leads to the AT1-IR association seen in MCF-7 cells in response to Ang II is the effect of longterm exposure to Ang II (two hours) since these effects are not prominent when the cells are exposed to Ang II for shorter time periods (less than one hour).

The NIH imageJ analysis of Fig. 3b showed that the intensities of $70 \mathrm{kDa}$ bands were comparable in all lysates before immunoprecipitation (Fig. 3g). The intensities of $45 \mathrm{kDa}$ bands were slightly lower in the lysates of cells that were exposed to Ang II for one hour and in the lysates of cells that were exposed to Ang II and losartan (Fig. 3h). However, they were similar in the lysates of cells that were not exposed to Ang II (lane 1, Fig. 3b) and in the lysates of cells exposed to Ang II for 2 hours (lane 3, Fig. 3b). Therefore, the 5fold increase in the levels of the $45 \mathrm{kDa}$ AT1 peptide, and the 15 fold increase in the levels of the $70 \mathrm{kDa}$ AT' 1 peptide that co-precipitated with the IR-beta in the MCF-7 cells exposed to Ang II for 2-hours could only result from an increased association of the AT1 and the IR in response to 2-hour exposure to Ang II.

\section{DISCUSSION}

Metabolic disorders such as type II diabetes, obesity and metabolic syndrome are added risk factors for women suffering from breast cancer and contribute to the increased death rate. Insulin resistance is a major underlying factor in all these patho-physiological conditions. One of the main characteristics of insulin resistance is the inability to induce IR-signaling even in the presence of normal or increased levels of insulin in the blood and structurally intact (not mutated) IR. Studies on insulin resistance are focused on the IRsignaling that contributes to the metabolic effects of insulin and down-stream signaling of IR (such as phosphorylation status of IR, IRS, PI-3 kinase $)^{[51-53]}$. These elegant studies have provided explanations for how metabolic effects of insulin are inhibited by AT1 via altering the functions of PI-3 kinase and other down-stream molecules that participate in normal IRsignaling in tissues such as rat heart and rat aorta smooth muscle cells. However, long-term effects of Ang II-exposure on IR-signaling (as in the case of patients suffering from hypertension and other metabolic disorders in which Renin-Angiotensin system is hyperactive) in epithelial cells that undergo malignant transformation is not addressed in these studies. In addition, studies to date that tested the effect of Ang II-exposure on the binding of insulin to IR have been performed for less than 1-hour exposure times, and were unable to detect any Ang II-mediated effect on insulin binding to IR. Such observations further supported the idea that the enhanced insulin sensitivity observed in response to treatment with losartan in both animal models with insulin resistance and in insulinsensitive cell types is due to cross-talk between downstream signaling molecules of AT1 and IR. It is expected that because IR-signaling contributes to both metabolic and mitogenic activities, situations that affect normal IR-signaling would complicate progression of cancer. Therefore, understanding the role of cross talk between signaling by Ang II and IR in the progression of breast cancer, a tissue for which Ang II acts as a mitogen, is imperative. We have taken a different approach in that we tested whether or not long term exposure to Ang II interferes with the ligand-receptor interaction of insulin and IR in MCF-7 cell line, a model system for breast epithelial cells that had undergone malignant transformation. Relevance of this study is particularly noteworthy given the fact that the AT1 receptor expression is enhanced in breast hyperplasia and in situ carcinoma ${ }^{[11]}$.

The studies described here for the first time demonstrate that activation of the AT1 for a period of 2-hours results in reduced overall binding of insulin to IR in epithelial cells such as breast cancer cells. However levels of the IR-beta in the cell are not affected by the long-term exposure to Ang II. In addition, these studies also show for the first time that the Ang II receptor AT1 associates with the IR-beta subunit in breast cancer cell line $\mathrm{MCF}-7$ in response to 
exposure to Ang II for a period of 2 hours and that high-molecular weight forms of AT1 receptor are present in these cells. All forms of the AT1 interact with the IR-beta in response to Ang II, because we observed increase in the intensity of both $45 \mathrm{kDa}$ and $70 \mathrm{kDa}$ bands visualized by anti-AT1 antibody after immunoblotting the protein complex immunoprecipitated by anti-IR-beta antibody.

What is striking about our observations is that the time taken to induce AT1-IR-beta association corresponds to the time taken for the AT1-mediated inhibition of ${ }^{125}$ I-insulin binding to IR in response to Ang II exposure. To date there are no reports that show existence of AT1-IR beta association in response to exposure to Ang II in any of the Ang II-responsive cell types. Thus, our results have unraveled a novel mechanism for the lack of IR-signaling in the breast cancer cells that have prominent AT1 expression, namely receptor level association of the AT1 that may contribute to sequestering functional IR in an AT1-IR complex and thus inhibiting the availability of functional IR to bind insulin (Fig. 4).In conclusion, Ang II-mediated association of AT1-IR-beta in breast cancer cells over expressing the AT1 receptor seems to occur without depleting the total amount of IR-beta in the cell. Such reduction in insulin binding to IR can lead to reduced normal IR-signaling in these cells and contribute to the complications of breast cancer. Thus, our results have unraveled a novel mechanism for the lack of IR-signaling in the breast cancer cells that have prominent AT1 expression, namely receptor level association of the AT1 that may contribute to sequestering functional IR in an AT1-IR complex and thus inhibiting the availability of functional IR to bind insulin (Fig. 4). A. possible pathway by which Ang II and AT1 can link breast cancer to lack of IR signaling and consequent insulin resistance is depicted in Fig. 5. Increases in the Ang II-activated AT1 in breast cancer cells could directly affect the levels of functional IR in these cells. This is consistent with the epidemiological observation that over expression of the AT1 and hyperactive RAS accompanies breast cell transformation and breast cancer. The observed AT1-IR beta association could be an after-effect of AT1-IR cross talk that has been described previously in response to shorter periods of Ang II-exposure in other insulin-sensitive cell types ${ }^{[51-53]}$. Alternatively, this could be an effect unique to breast epithelial cells that express specific signaling molecules to function as platforms for associating activated AT1 receptor with neighboring IR-beta molecules on the membrane.

\section{ACKNOWLEDGMENTS}

This work was partly supported by NIH grant \# HL060241-02 and DoD Concept Award Project No: BC996085 to LP. We thank members of PulakatGavini lab for helpful discussions.

\section{REFERENCES}

1. Lorincz A. M. and S. Sukumar, 2006. Molecular links between obesity and breast cancer. Endocr Relat Cancer.13: 279-92.

2. Carmichael, A. R. 2006. Obesity and prognosis of Breast Cancer. Obesity Reviews. 7:333-340

3. Boyd D. B. 2003. Insulin and Cancer. Integr Cancer Ther. 2:315-29.

4. Pasanisi, P, F. M. Barrino, E. De Petris, E. Venturelli, A. Mastroianni and S. Panico. 2006. Metabolic syndrome as a prognostic factor for breast cancer recurrences. Int J Cancer. 119, 236238

5. Kuhl, H. 2005. Breast cancer risk in the WHI study: the problem of obesity. Maturitas. 51:83-97

6. Gustamacchia, E., F. Resta, V, Triggiani, A. Liso, B. Licchelli, S. Ghiyasaldin, C. Sabba, and E. Tafaro. 2004. Evidence for a putative relationship between type 2 diabetes and neoplasia with particular reference to breast cancer: role of hormones, growth factors and specific receptors. Curr Drug Targets Immune Endocr Metabol Disord. 4: 59-66

7. Lipscomb, L. L. P. J. Goodwin, B. Zinman, J. R. Mc Laughin, and J. E. Hux. 2006 Diabetes mellitus and breast cancer: a retrospective population-based cohort study. Breast Cancer Res Treat. 98: 349-56.

8. Puddefoot, J. R, U. K. Udeozo, S. Barker, and G. P. Vinson. 2006. The role of angiotensin II in the regulation of breast cancer cell adhesion and invasion. Endocr Relat Cancer. 13: 895-903

9. Greco, S., S. A. Muscella, M. G. Elia, P. Salvatore, C. Storelli, A. Mazzotta, C. Manca, and S. Marsigliante. 2003. Angiotensin II activates extracellular signal regulated kinases via protein kinase $\mathrm{C}$ and epidermal growth factor receptor in breast cancer cells. J Cell Physiol. 196: 370-7

10. Lim, K. T., N. Cosgrave, A. D. Hill, and L. S. Young, 2006. Nongenomic oestrogen signalling in oestrogen receptor negative breast cancer cells: a role for the angiotensin II receptor AT1. Breast Cancer Res. 8: R33 
11. De Paepe, B., V. L. Verstraeten, C. R. De Potter, L. A.Vakaet, and G. R. Bullock, 2001. Growth stimulatory angiotensin II type-1 receptor is upregulated in breast hyperplasia and in situ carcinoma but not in invasive carcinoma. Histochem Cell Biol. 116: 247-54

12. Koh, W. P., J. M. Yuan, D. Van Den Berg, H. P. Lee and M. C. Yu, 2005 Polymorphisms in angiotensin II type 1 receptor and angiotensin Iconverting enzyme genes and breast cancer risk among Chinese women in Singapore Carcinogenesis 26: 459-464

13. Haffner, S. M., L. Ruilope, B. Dahlof, E. Abadie, S. Kupfer, and F. J. Zannad, 2006. J. Metabolic syndrome, new onset diabetes, and new end points in cardiovascular trials.Cardiovasc Pharmacol. 47: 469-475

14. Chakraborty C. 2006. Biochemical and molecular basis of insulin resistance. Curr Protein Pept Sci. 7(2):113-21

15. Cooper, M. E., C. Tikellis, and M. C. Thomas 2006. Preventing diabetes in patients with hypertension: one more reason to block the reninangiotensin system J Hypertens Suppl. 24, S57-63

16. Cheung, B. M. 2006. Therapeutic potential of angiotensin receptor blockers in hypertension Expert Opin. Investig Drugs. 15, 625-635

17. Danilczyk, U. and J. M. Penninger, 2006. Angiotensin-converting enzyme II in the heart and the kidney. Circ Res. 98:463-471.

18. Ibrahim, M. M. 2006. RAS inhibition in hypertension. J Hum Hypertens. 20:101-108.

19. Takemori, K., H. Ishida, and H. Ito, 2005. Continuous inhibition of the renin-angiotensin system and protection from hypertensive end-organ damage by brief treatment with angiotensin II type 1 receptor blocker in stroke-prone spontaneously hypertensive rats. Life Sci. 77: 2233-2245

20. Iwashima, Y., M. Okada, M. Haneda, and T. Yoshida, 2006. Regression of cardiac hypertrophy in type 2 diabetes with hypertension by candesartan Res Clin Pract. 74: 8-14

21. Chu, K. Y., T. Lau, P. O. Carlsson, and P. S. Leung, 2006. Angiotensin II type 1 receptor blockade improves beta-cell function and glucose tolerance in a mouse model of type 2 diabetes Diabetes. 55: 367-74

22. Hsieh, P. S. 2005. Reversal of fructose-induced hypertension and insulin resistance by chronic losartan treatment is independent of AT2 receptor activation in rats. J Hypertens. 23: 2209-2217
23. Rugale, C., Cordaillat, M., Mimran, A. and Jover, B. 2005. Prevention and reversal by enalapril of target organ damage in angiotensin II hypertension Clin. Exp. Hypertens. 28: 121-32

24. Umeda, M., Knada, T. and Murakami, T. (2006) Effects of angiotensin II receptor antagonists on insulin resistance syndrome and leptin in sucrosefed spontaneously hypertensive rats.Hypertens Res. 26: 485-492

25. Yamagishi, S., K. Tanaka, and H. Inoue, 2006. Role of insulin-sensitizing property of telmisartan, a commercially available angiotensin II type 1 receptor blocker in preventing the development of atrial fibrillationMed Hypotheses. 66: 118-120

26. Murphy, T. J., K. Takeuch, R. W. and Alexander, 1992. Molecular cloning of AT1 angiotensin receptors. Am J Hypertens. 5: 236S-242S

27. Saito, Y. and B. C. Berk 2002. Angiotensin IImediated signal transduction pathways. Curr. Hypertens. Rep. 4:167-17

28. Matute, C., L. Pulakat, C. Rio, C. Valcarcel, and R Miledi, 1994. Properties of angiotensin II receptors in glial cells from the adult corpus callosum. Proc. Natl. Acad. Sci. USA. 91:3774-3778

29. Yin, G., C. Yan, C. and B. C. Berk, 2003. Angiotensin II signaling pathways mediated by tyrosine kinases. .J. Biochem. Cell. Biol. 35: 780783

30. Marrero M. B., B. Schieffer, W. G. Paxton, L. Heerdt, B. C. Berk, P. Delafontaine, and K. E. Bernstein, 1995. Direct stimulation of Jak/STAT pathway by the angiotensin II AT1 receptor. Nature. 375: 247-50

31. Venema, R. C., H. Ju, V. J. Venema, B. Schieffer, J. B. Harp, B. N. Ling, D. C. Eaton and M. B. Marrero, 1998 Angiotensin II-induced association of phospholipase Cgamma1 with the G-proteincoupled AT1 receptor. J Biol Chem. 273: 77037708

32. AbdAlla, S., H. Lother, H., A. M. Abdel-tawab and U. Quitterer, 2001. The angiotensin II AT2 receptor is an AT1 receptor antagonist. J Biol Chem. 276: 39721-39726

33. AbdAlla, S., H. Lother, and U. Quitterer, 2000. AT1-receptor heterodimers show enhanced Gprotein activation and altered receptor sequestration. Nature. 407: 94-98

34. Seta, K. and J. J. Sadoshima, 2003. Phosphorylation of tyrosine 319 of the angiotensin II type 1 receptor mediates angiotensin II-induced trans-activation of the epidermal growth factor receptor. J Biol Chem. 278: 9019-9026 
35. White M. F., and C. R. Kahn, 1994. The insulin signaling system. .J. Biol. Chem. 269: 1-4

36. Backer, J. M., G.G. Schroeder, C. R. Kahn, M. G. Myers, Jr., P. A. Wilden, D. A. Cahill, and M. F. White. 1992. Insulin stimulation of phosphatidylinositol 3-kinase activity maps to insulin receptor regions required for endogenous substrate phosphorylation. J Biol Chem. 267: 1367-1374.

37. Muller-Wieland, D., T. Taub, D. S. Tewari, K. M. Kriauciunas, S. Sethu, K. Reddy, and C. R. Kahn, 1989. Insulin-receptor gene and its expression in patients with insulin resistance. Diabetes. 38: 3138

38. Pirola, L., A. M. Johnston, and E. Van Obberghen, 2004. Modulation of insulin action. Diabetologia. 47: 170-84

39. Morse, S. A., R. Zhang, V. Thakur, and E. Reisin, E. 2005. Hypertension and the metabolic syndrome. Am J Med Sci. 330: 303-310

40. Simstein, R., M. Burow, A. Parker, C. Weldon, and B. Beckman, 2003. Apoptosis, chemoresistance, and breast cancer: insights from the MCF-7 cell model system. Exp Biol Med (Maywood). 228: 995-1003

41. Greco, S., M. G. Elia, A. Muscella, C. Storelli, and S. J. Marsigliante, 2002. AT1 angiotensin II receptor mediates intracellular calcium mobilization in normal and cancerous breast cells in primary culture. Cell Calcium. 32: 1-10

42. Muscella, A., S. Greco, M. G Elia, C. Storelli, and S. J. Marsigliante, 2002. Angiotensin II stimulation of $\mathrm{Na}+\mathrm{K}+\mathrm{ATPase}$ activity and cell growth by calcium-independent pathway in $\mathrm{MCF}-7$ breast cancer cells. Endocrinol. 173: 315-323

43. Muscella, A., S. Greco, M. G. Elia, Storelli, C. and Marsigliante, S. J. (2003). Angiotensin II activates extracellular signal regulated kinases via protein kinase $\mathrm{C}$ and epidermal growth factor receptor in breast cancer cells. J. Cell. Physiol. 197: 61-68

44. Sartori, M., G. Ceolotto, I. Papparella, E. Baritono, L. Ciccariello, L. Calo, M. Leoni, and A. Semplicini, 2004. Effects of angiotensin II and insulin on ERK1/2 activation in fibroblasts from hypertensive patients.Am. J. Hypertens. 17: 604-10
45. Pulakat, L., S. Rahman, A. Gray, D. Knowle, and N. Gavini, 2005. Roles of the intracellular regions of angiotensin II receptor AT2 in mediating reduction of intracellular cGMP levels. Cell Signal. 17: 395-404

46. Pulakat, L., A. S. Tadessee, J. J. Dittus, and N. Gavini, 1998. Role of Lys215 located in the fifth transmembrane domain of the AT2 receptor in ligand-receptor interaction. Regul Pept. 73: 51-57

47. Pulakat, L., S. Cooper, D. Knowle, C. Mandavia, S. Bruhl, M. Hetrick, and N. Gavini, (2005) Ligand-dependent complex formation between the Angiotensin II receptor subtype AT2 and $\mathrm{Na}+\mathrm{H}+$ exchanger NHE6 in mammalian cells. Peptides, 26: 863-873

48. Juan C. C, Y. Chien Y, Wu LY, Yang WM, Chang CL, Lai YH, Ho PH, Kwok CF, Ho LT. (2005)Angiotensin II enhances insulin sensitivity in vitro and in vivo. Endocrinology, 146:52246-54

49. Al. Qatan, K. K., S. J. Al-Akhawand, and M. H. Mansour, (2006) Immunohistochemical localization of distinct angiotensin II AT1 receptor isoforms in the kidneys of the Sprague-Dawley rat and the desert rodent Meriones crassus. Anat. Histol. Embryol. 35: 130-138.

50. ImageJ. http://rsb.info.nih.gov/ij/

51. Carvalheira, J. B., V. C. Calegari, H. G. Zecchin, W. Nadruz, Jr, R. B. Guimaraes, E. B. Ribeiro, K. G. Franchini, L. A. Velloso, and M. J. Saad, (2003) The cross-talk between angiotensin and insulin differentially affects phosphatidylinositol 3kinase- and mitogen-activated protein kinasemediated signaling in rat heart: implications for insulin resistance. .Endocrinol. 144: 5604-14

52. Velloso, L. A.., F. Folli, X. J. Sun, M. F. White, M. J. Saad, and C. R. Kahn, (1996) Cross-talk between the insulin and angiotensin signaling systems. .Proc. Natl. Acad. Sci. 93: 12490-5

53. Folli, F., M. J. Saad, L. Velloso, H. Hansen, O. Carandente, E. P. Feener, and C. R. Kahn (1999) Crosstalk between insulin and angiotensin II signalling systems. Exp. Clin. Endocrinol. Diabetes. 107: 133-9 